(2) Open Access Full Text Article

REVIEW

\title{
Shigatoxin-associated hemolytic uremic syndrome: current molecular mechanisms and future therapies
}

This article was published in the following Dove Press journal:

Drug Design, Development and Therapy

18 July 2012

Number of times this article has been viewed

\author{
Lindsay S Keir' \\ Stephen D Marks \\ Jon Jin $\mathrm{Kim}^{2}$ \\ 'Academic Renal Unit, University \\ of Bristol, Bristol; ${ }^{2}$ Department of \\ Paediatric Nephrology, Great Ormond \\ Street Hospital NHS Foundation Trust, \\ London, United Kingdom
}

\begin{abstract}
Hemolytic uremic syndrome is the leading cause of acute kidney injury in childhood. Ninety percent of cases are secondary to gastrointestinal infection with shigatoxin-producing bacteria. In this review, we discuss the molecular mechanisms of shigatoxin leading to hemolytic uremic syndrome and the emerging role of the complement system and vascular endothelial growth factor in its pathogenesis. We also review the evidence for treatment options to date, in particular antibiotics, plasma exchange, and immunoadsorption, and link this to the molecular pathology. Finally, we discuss future avenues of treatment, including shigatoxin-binding agents and complement inhibitors, such as eculizumab.

Keywords: hemolytic uremic syndrome, shigatoxin, diarrhea, Escherichia coli, complement, alternative pathway, eculizumab
\end{abstract}

\section{Introduction}

Hemolytic uremic syndrome is the leading cause of acute kidney injury in childhood and has significant morbidity and mortality, with up to $5 \%$ mortality rate and a $25 \%$ risk of developing chronic kidney disease, proteinuria, or hypertension. ${ }^{1,2}$ Diarrhea-associated hemolytic uremic syndrome (D+HUS) accounts for $90 \%$ of all cases of hemolytic uremic syndrome. It is usually caused by Escherichia coli $\mathrm{O} 157$ and is more common in children under 5 years of age. ${ }^{1,3}$ The worldwide incidence is $0.2-4$ cases per 100,000 per year, ${ }^{4}$ but this is higher in children younger than 5 years, at approximately six cases per 100,000 per year. ${ }^{1}$ There is also geographical variation, ${ }^{5}$ with the highest incidence worldwide reported in Argentina (10.5 per 100,000 per year ${ }^{6}$ ) whilst in the UK, Scotland has higher rates (1.56 [3.4 under 5 years of age] versus 0.71 [1.54 under 5 years of age] UK average per 100,000 per year ${ }^{7}$ ). It is unclear why this is the case, but may relate to epidemics, with a greater proportion of cattle farmers per head of population seen in these countries, because the natural reservoir of E. coli $\mathrm{O} 157$ is cattle and other ruminants. In addition, it has been suggested that lower summer temperatures and greater rainfall in the UK may contribute to the higher incidence seen in Scotland.

\section{Clinical course}

Hemolytic uremic syndrome is characterized clinically by the triad of microangiopathic hemolytic anemia, thrombocytopenia, and acute kidney injury. ${ }^{1,5}$ In D+HUS, patients contract a shigatoxin-producing bacterial infection, usually E. coli O157:H7, which
Department of Paediatric Nephrology, Great Ormond Street Hospital NHS

Foundation Trust, London WCIN 3JH, United Kingdom

Tel +442074059200

Fax +442078138259

Email jonjinkim@doctors.org.uk 
causes a diarrheal illness, with a $10 \%-15 \%$ risk of developing hemolytic uremic syndrome, although different strains have varying virulence. For example, E. coli O104:H4 from the German outbreak in 2011 carried a 25\% risk of developing hemolytic uremic syndrome. ${ }^{8}$

After being infected by $E$. coli, patients develop diarrhea 2-5 days later. ${ }^{1}$ The diarrhea is usually profuse and often bloody, representing hemorrhagic colitis. Three to 8 days later, signs of hemolytic uremic syndrome manifest in those who are susceptible. Clinical features include fatigue, pallor, and oligoanuric acute kidney injury, with fluid overload, hypertension, and edema. The clinical course varies, with milder cases avoiding renal replacement therapy and being managed with careful fluid and electrolyte management, nutritional support, and control of hypertension. ${ }^{1,3}$ Patients with more severe presentation and anuria are likely to require dialysis. ${ }^{9}$ More severely affected patients can show signs of other organ involvement, most notably cerebral and pancreatic involvement. ${ }^{9,10}$ Cerebral hemolytic uremic syndrome can manifest in several ways, including irritability, altered level of consciousness, and seizures, with signs occurring after onset of hemolytic uremic syndrome. Previous reports suggest that 3\%-41\% of patients develop cerebral hemolytic uremic syndrome. ${ }^{9,10}$ One clinical study suggested that $50 \%$ of patients with hemolytic uremic syndrome have abnormal electroencephalograms. ${ }^{11}$ There can be other multiorgan involvement, including the liver and heart. ${ }^{1,9,10}$

There is a variable prognosis associated with hemolytic uremic syndrome, although those with a milder clinical course gradually improve, with resolution of renal impairment over a few weeks. ${ }^{2}$ Those with a more severe course can take longer. Approximately 15\%-25\% have residual renal defects, which range from persistent proteinuria and hypertension to end-stage renal disease. Oligoanuria persisting for more than 4 weeks increases the chance of a poor prognosis. ${ }^{2}$ Cerebral involvement may also have an impact on outcome, with one report suggesting 50\% recovery without long-term complications, and a $17 \%$ mortality rate in those with cerebral disease in association with D+HUS. ${ }^{10}$ Another report suggests one third of cases have a long-term neurological deficit after hemolytic uremic syndrome involving the central nervous system. ${ }^{12}$

There is no specific treatment for D+HUS, with current management focusing on supportive therapy. Clinical care involves fluid and electrolyte balance, management of hypertension, nutritional support, and renal replacement therapy if required. It is hoped that by understanding the pathogenesis of D+HUS better, a more direct treatment modality/strategy can be developed.

\section{Pathogenesis of hemolytic uremic syndrome}

$\mathrm{D}+\mathrm{HUS}$ is a toxin-mediated disease, because $E$. coli bacteria containing shigatoxin-producing genes (usually E. coli O157) infect the gastrointestinal tract, causing a diarrheal illness. The bacteria infect the large intestine and destroy the brush border microvilli. ${ }^{13}$ They produce shigatoxin which crosses the gastrointestinal epithelium and enters the circulation. It is not understood precisely how the shigatoxin does this, but binding to $\mathrm{Gb} 4$ (globotriosylceramide) receptors on colonic epithelial cells may mediate the process. ${ }^{14}$ Shigatoxin enters the circulation and targets cells which possess Gb3 receptors. Shigatoxin has never been detected in the blood of patients with D+HUS. ${ }^{15}$ It is hypothesized to circulate bound to polymorphonuclear leucocytes, but this remains controversial. ${ }^{13,17}$ Other blood cells have also been implicated in the carriage of shigatoxin, such as erythrocytes and platelets. ${ }^{18,19}$ It has been hypothesized that shigatoxin circulates bound to blood cells but not attached to $\mathrm{Gb} 3$ receptors. ${ }^{17}$ Instead, it binds to an as yet undetermined receptor which has much less affinity for shigatoxin. Therefore, when the shigatoxin finds its way to an organ which expresses Gb3, the shigatoxin preferentially detaches from a circulating blood cell and binds to the organ or tissue expressing Gb3.

$\mathrm{Gb3}$ is a glycosphingolipid which is expressed in the kidney, brain, liver, pancreas, heart, and hemopoetic cells. ${ }^{17,20-22}$ Shigatoxin binds to Gb3 via its pentameric B subunit. When shigatoxin binds cellular Gb3, it is internalized by endocytosis and trafficked by vesicular carriers to the endoplasmic reticulum via early endosomes, the trans-Golgi network, and the Golgi stacks (retrograde transport). ${ }^{23}$ In the endoplasmic reticulum, the active A subunit is reduced from its B subunit. The A subunit unfolds and partially inserts into the endoplasmic reticulum membrane. Here it mimics a misfolded membrane-associated protein and utilizes the cell's own endoplasmic reticulum-associated protein degradation pathway. This normally functions to remove misfolded proteins and stray subunits from the endoplasmic reticulum to maintain homeostasis. ${ }^{24}$ The A subunit then translocates to the cytosol using an energy-dependent host cell mechanism. Here the A subunit proteins are "refolded" to form the enzymatically active A1 fragment which exerts toxic effects. It causes depurination of adenosine at a highly conserved loop of $28 \mathrm{~S}$ ribosomal RNA of the $60 \mathrm{~S}$ ribosomal subunit, which in turn causes cessation of protein synthesis and ultimately 
cell death. Some have suggested that shigatoxin also targets nuclear DNA, causing fragmentation which leads to apoptosis, but this mechanism is not well defined. ${ }^{25}$

There is some evidence that lower levels of shigatoxin may not cause cell death but may instead cause increased protein synthesis, particularly with the production of cytokines and chemokines, and expression of the adhesion molecule. The intracellular events leading to this are not clearly defined. ${ }^{26,27}$

There are two main subtypes of shigatoxin, ie, shigatoxins 1 and 2. They display 57\% and 60\% nucleotide sequence homology in the A and B subunits, respectively. ${ }^{28}$ Shigatoxins 1 and 2 have $56 \%$ amino acid homology and as such are immunologically distinct entities. ${ }^{23}$ The B subunits show identical binding affinity to $\mathrm{Gb3}$, and the A subunits have equal N-glycosidase activity. ${ }^{29}$ Shigatoxin 2 is more closely associated with human disease. There have been reports of different cellular responses to shigatoxin 1 and shigatoxin $2 .{ }^{30}$ One group reported that microvascular endothelial cells in the brain were more responsive than macrovascular endothelial cells to the cytotoxic effects of shigatoxin $2 .{ }^{31}$ There is evidence that the fatty acid composition of $\mathrm{Gb} 3$ receptor influences intracellular trafficking, either directing shigatoxin as described above or sending the toxin to lysosomes for degradation. ${ }^{32}$ The presence of the receptor in detergent-resistant membranes may also influence this. ${ }^{33}$

It is unclear why the kidney is the main target of this disease. However, the glomerulus in humans is a prime toxin target. Pathologically, glomerular thrombotic microangiopathy is seen after shigatoxin exposure. ${ }^{34,35}$ Thrombotic microangiopathy describes the features of endothelial proliferation, swelling, and detachment from the basement membrane, increased vessel wall thickness, subendothelial deposits, and platelet aggregation with microthrombi formation, resulting in vessel narrowing which causes red cell damage (see Figure 1). ${ }^{34,35}$ The endothelial cell appears to be the main focus of this disease, given the pathology seen. Shigatoxin binds to Gb3 receptors on endothelial cells. One group showed that shigatoxin acted via $N F-\kappa \beta$ to elicit cytokine production from glomerular endothelial cells, eg, interleukin-8. Shigatoxin also triggers endothelial cells to express adhesion molecules, such as $\mathrm{P}$-selectin, which attracts

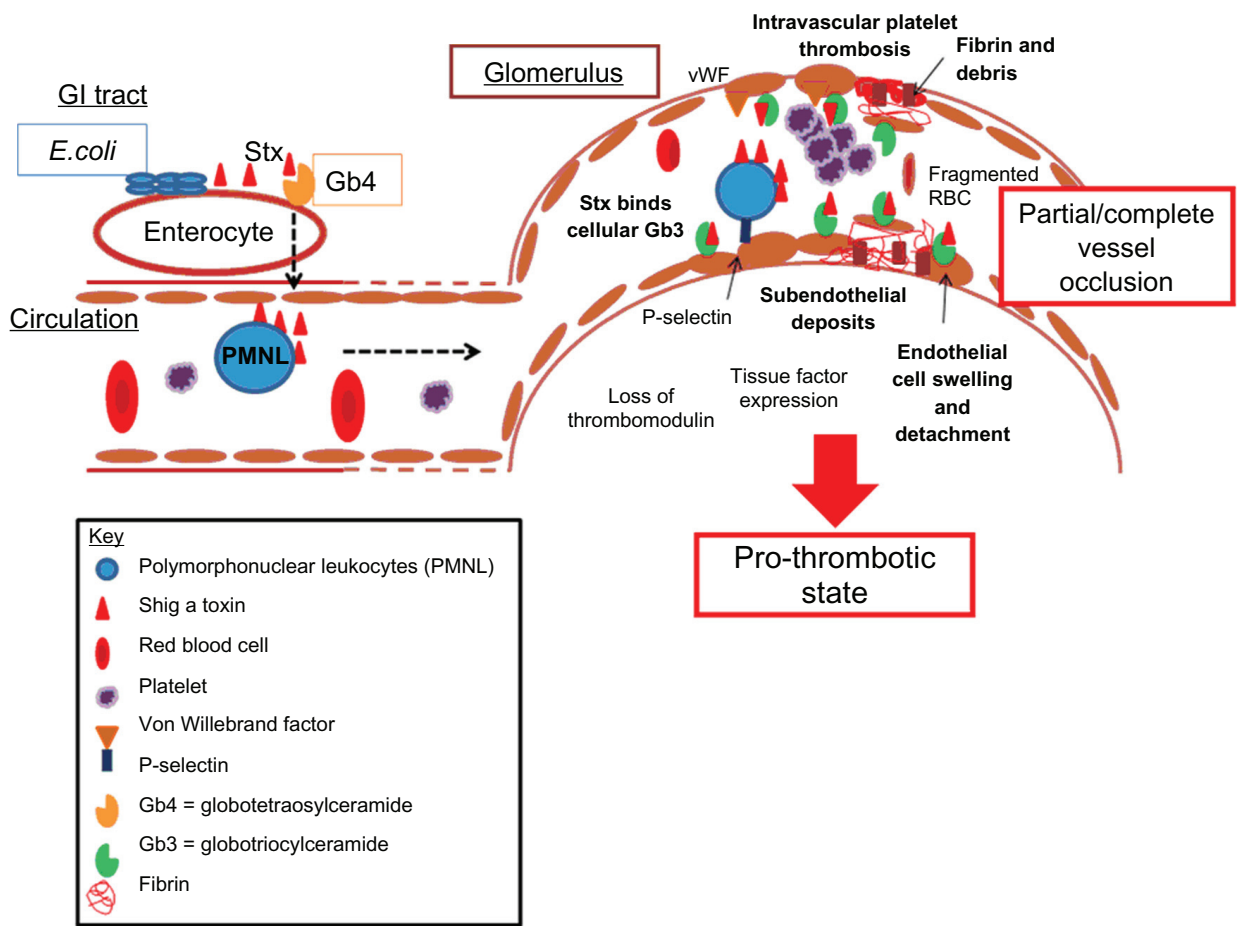

Figure I Thrombotic microangiopathy.

Notes: After infection with a shigatoxin-producing organism, shigatoxin enters the circulation, possibly via Gb4 receptors. On entering the microcirculation, it circulates, probably bound to polymorphonuclear leukocytes. These cells deliver shigatoxin to vulnerable endothelial cells which express Gb3 receptors. There is a higher affinity of shigatoxin for Gb3 receptors and so it dissociates from polymorphonuclear leukocytes. This triggers a proinflammatory and prothrombotic cascade. Endothelial cells express adhesion molecules like P-selectin, which attract neutrophils. They also produce proinflammatory cytokines. There is expression of von Willebrand factor which attracts platelets. Tissue factor, a prothrombotic and proinflammatory molecule, is expressed. There is loss of the thromboprotective receptor, thrombomodulin. The result is thrombotic microangiopathy which is characterized by swelling and detachment of endothelial cells with exposure of the subendothelial matrix. There is accumulation of debris in the subendothelial space. Platelets aggregate and fibrin is deposited. There is partial or complete vessel occlusion with microthrombi formation. Red cells are damaged and fragmented by the vessel occlusion and increased sheer stress. 
leucocytes to the glomerulus. ${ }^{26}$ Thromboresistant properties are lost, triggering the prothrombotic cascade. Thrombomodulin expression is reduced in response to shigatoxin, ${ }^{36}$ whilst expression of von Willebrand factor attracts platelets to the glomerulus resulting in microthrombi formation. Shigatoxin may also inhibit the cleavage of von Willebrand factor platelet strings by ADAMTS13, thus perpetuating the prothrombotic environment. ${ }^{37}$ Tissue factor expression by endothelial cells also contributes to the prothrombotic, proinflammatory cascade, with the end result of glomerular thrombotic microangiopathy. ${ }^{38}$

It is not only endothelial cells which are vulnerable to shigatoxin. Podocytes express Gb3 receptors and are therefore a potential target. ${ }^{39} \mathrm{mRNA}$ of podocyte-specific markers has been found in the urine of children with D+HUS. ${ }^{40}$ This suggests that podocytes may also be damaged by shigatoxin. Renal tubules express Gb3 in humans, and can be toxin targets. ${ }^{41} \mathrm{~A}$ glomerular disease pattern in response to shigatoxin is not seen in all animals. Mice and rats lack glomerular Gb3 expression and develop a tubular phenotype after exposure to shigatoxin. ${ }^{20}$ Cells of the central nervous system also express Gb3 receptors, including neurones and endothelial cells. Human microvascular endothelial brain cells express Gb3, but only after treatment with tumor necrosis factor alpha. It is known that Gb3 expression can be induced by several proinflammatory cytokines.

Our understanding of the pathogenesis of D+HUS is not complete (Figure 1). It is unclear why the kidney is particularly vulnerable to attack by shigatoxin. Recent advances have changed the direction of investigation into the pathogenesis of hemolytic uremic syndrome. Dysregulation of the alternative complement pathway has been identified as the cause of the rarer atypical hemolytic uremic syndrome which accounts for less than $10 \%$ of all cases of the syndrome. ${ }^{42}$ There may also be a role for vascular endothelial growth factor (VEGF) in the pathogenesis of hemolytic uremic syndrome, because VEGF inhibitors, such as bevicuzimab, used in cancer treatment regimens for their antiangiogenic properties cause glomerular thrombotic microangiopathy as an unexpected side effect. ${ }^{43}$ Furthermore, an inducible podocyte specific knockdown of VEGF A in adult mice results in glomerular thrombotic microangiopathy.

\section{Complement in D+HUS}

The role of complement in D+HUS is a source of much interest, given its role in the pathogenesis of atypical hemolytic uremic syndrome. ${ }^{42}$ Several members of the alternative complement pathway are mutated in patients with familial hemolytic uremic syndrome. There are now over 200 reported mutations associated with the disease. ${ }^{44}$ These mutations result in overactivation of the alternative pathway, either by loss of regulatory functions (eg, factor $\mathrm{H}^{45}$, factor $\mathrm{I}^{46}, \mathrm{CD}^{4} 6^{47}$ ) or by gaining persistent or enhanced activation (eg, factor $\mathrm{B}^{48}, \mathrm{C} 3^{49}$ ). Mutations in thrombomodulin, which regulates complement and the coagulation cascade, have also been described. ${ }^{50}$ Through study of these patients, it became clear that abnormal alternative pathway activation can lead to development of glomerular thrombotic microangiopathy, with consideration of the potential role of complement in shigatoxin-associated hemolytic uremic syndrome.

The alternative pathway is one of three avenues which result in activation of the complement cascade. It does not require pathogen/antigen-antibody complexes to become active. There is a constant "tick over" of the alternative pathway, with spontaneous hydrolysis of C3 in serum. ${ }^{51,52}$ This produces the anaphylatoxin, $\mathrm{C} 3 \mathrm{a}$, which is proinflammatory, and $\mathrm{C} 3 \mathrm{~b}$, which can bind to the surface of cells (see Figure 2). In order to prevent the complement cascade being activated against the body's own cells, there are regulatory mechanisms in place to keep this "tick over" in check. These include serum-based and cell-based factors which can inactivate $\mathrm{C} 3 \mathrm{~b}$ when it is produced (see Figure 3). ${ }^{50-52}$ Serum-based factors include complement factor $\mathrm{H}$ and factor I. The cell-based receptors include CD46 or membrane cofactor protein and thrombomodulin. Mutations in all these regulatory molecules have been described in patients with atypical hemolytic uremic syndrome. With loss of any one of these regulators through mutation or autoantibodies, there is uncontrolled activation of the alternative pathway and self-cells become targets of complement activation. The kidney seems to be particularly vulnerable, suggesting an important role for complement in the glomerulus.

Given the importance of complement in atypical hemolytic uremic syndrome, research attention has turned to investigate its potential role in the pathogenesis of D+HUS. The first evidence for a role of the alternative complement pathway in shigatoxin-associated hemolytic uremic syndrome was the observation that affected patients who have low serum $\mathrm{C}^{53}$, high $\mathrm{C} 3 \mathrm{~d}^{54}$ (breakdown product of $\mathrm{C} 3$ ), high plasma $\mathrm{Bb}$, and soluble C5b-9. ${ }^{55}$ Orth et $\mathrm{al}^{56}$ showed that purified shigatoxin 2 can bind to the regulatory protein, complement factor $\mathrm{H}$. This does not affect its ability to regulate the alternative complement pathway in the fluid/serum phase but does impede its ability to bind to cell membranes and prevent complement attack. This suggests that shigatoxin may lead to 


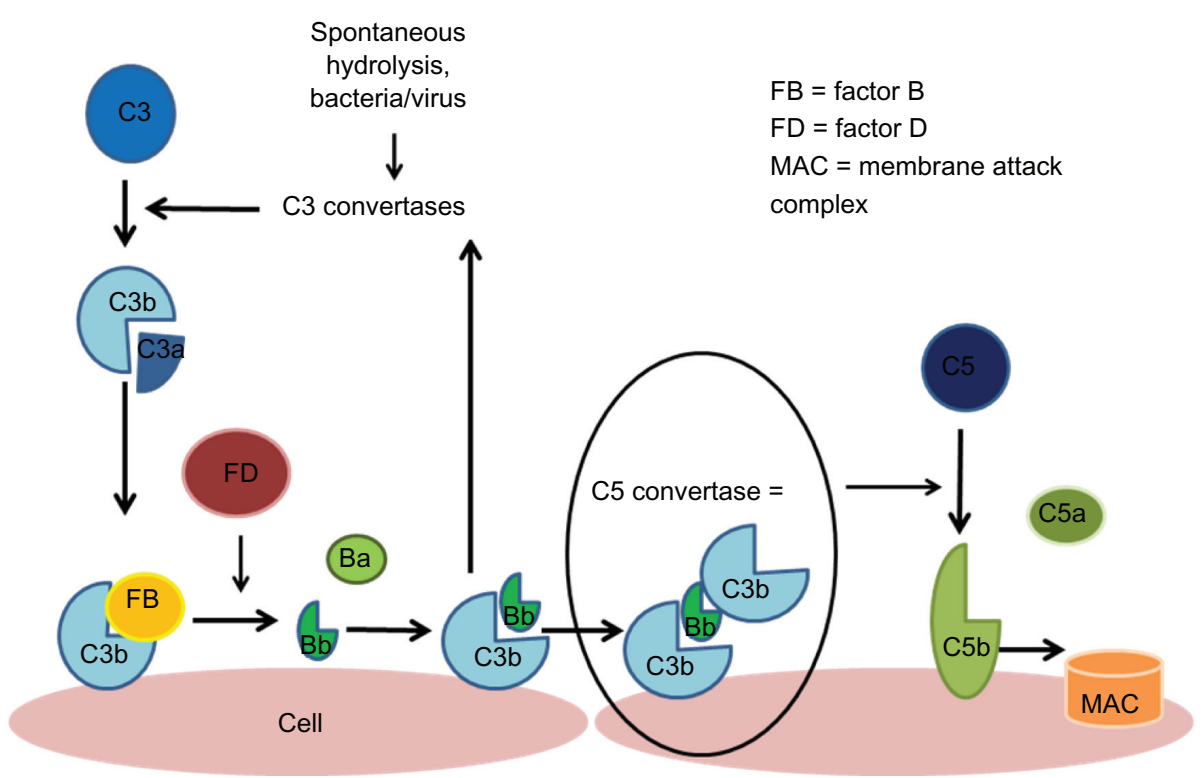

Figure 2 Alternative complement pathway.

Notes: The alternative pathway is triggered by the hydrolysis of $\mathrm{C} 3$ which forms $\mathrm{C} 3 \mathrm{a}$ and $\mathrm{C} 3 \mathrm{~b}$. C3b becomes bound to the cell surface and is then able to interact with factor $\mathrm{B}$, which is cleaved by factor $\mathrm{D}$, creating the $\mathrm{Bb}$ fragment which binds to other surface-bound $\mathrm{C} 3 \mathrm{~b}$ molecules to form $\mathrm{C} 3 \mathrm{bBb}$; the $\mathrm{C} 3$ convertase of the alternative pathway triggers an amplification loop, with further hydrolysis of $\mathrm{C} 3$. Ultimately, there is further production of C3b which joins with $\mathrm{C} 3$ convertase to form $\mathrm{C} 5$ convertase which cleaves $\mathrm{C} 5$ to $\mathrm{C} 5 \mathrm{a}$ and $\mathrm{C} 5 \mathrm{~b}$, and this leads to formation of an membrane attack complex. ${ }^{108}$

an acquired form of complement dysfunction and activation contributing to the disease process.

Morigi et $\mathrm{al}^{57}$ reported that shigatoxin caused dermal microvascular endothelial cells to express P-selectin which bound and activated $\mathrm{C} 3$ via the alternative pathway. C3 activation led to $\mathrm{C} 3$ a production, which upregulated $\mathrm{P}$-selectin expression. Under flow conditions, thrombi formed. A reduction in thrombomodulin expression was also seen. This had been reported before by Fernandez et $\mathrm{al}^{36}$ in glomerular endothelial cells. The loss of thrombomodulin potentially puts

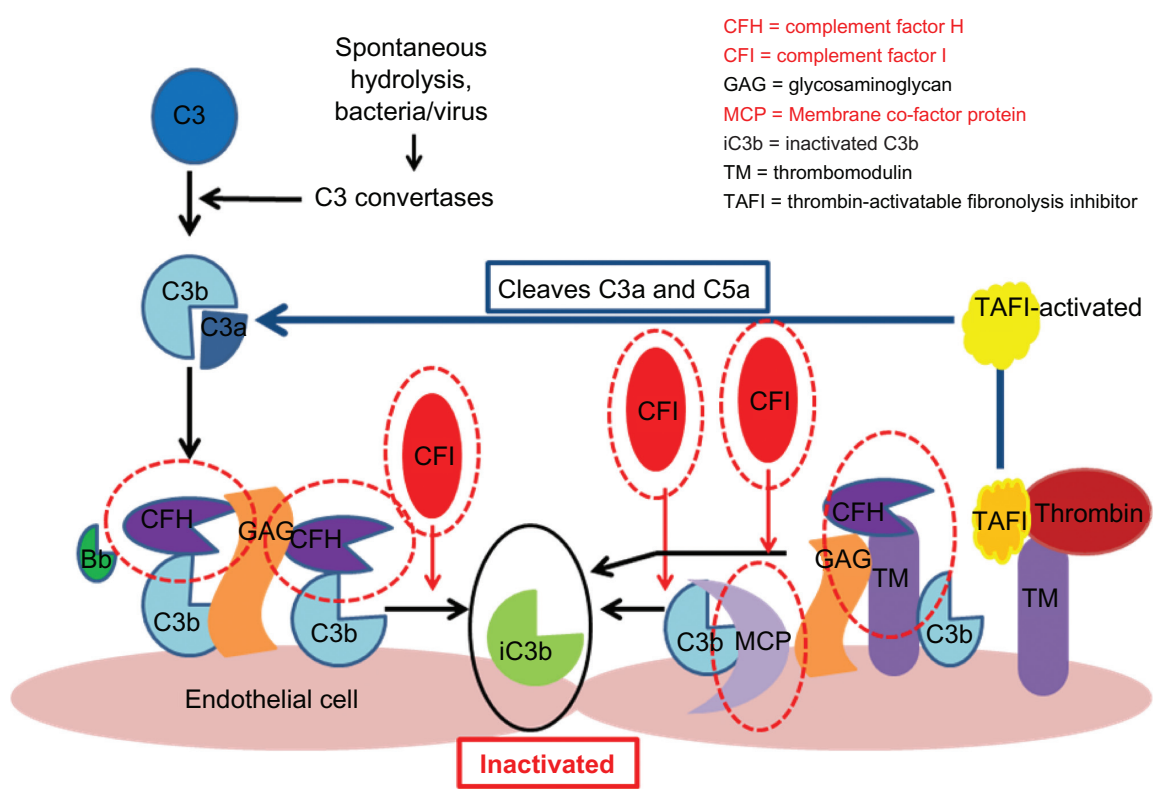

Figure 3 Regulation of the alternative pathway.

Notes: Complement regulators are shown circled in red. These include factor $\mathrm{H}$ and factor I and membrane cofactor protein. Each acts to promote inactivation of $\mathrm{C} 3 \mathrm{~b}$ and prevent further progression of the complement cascade. Factor $\mathrm{H}$ binds $\mathrm{C} 3 \mathrm{~b}$ and works with factor I to inactivate it. Both complement factor $\mathrm{H}$ and $\mathrm{I}$ are serum-based. Membrane cofactor protein is cell-bound. It also binds to $\mathrm{C} 3 \mathrm{~b}$ which has become attached to cells and works with factor I to inactivate it. Thrombomodulin is also shown because mutations have been associated with atypical hemolytic uremic syndrome. Thrombomodulin regulates complement by acting to inactivate the proinflammatory mediators, $\mathrm{C} 3 \mathrm{a}$ and $\mathrm{C} 5 \mathrm{a}$, and by accelerating factor I-mediated C3b inactivation. Thrombomodulin also plays a role in regulation of local coagulation via its interactions with thrombin. ${ }^{108}$ 
cells at risk of activation of the alternative pathway. Furthermore, in a murine model of shigatoxin-associated hemolytic uremic syndrome, factor B-deficient mice were protected from glomerular abnormalities and renal impairment. This suggests a role for the alternative pathway in shigatoxinassociated hemolytic uremic syndrome because factor B is an important procomplement activator. However, there is species variation in response to shigatoxin, and mice do not usually develop glomerular thrombotic microangiopathy because of lack of Gb3 expression in their glomerular cells.

Thurman et $\mathrm{al}^{55}$ reported that patients with D+HUS show elevated plasma $\mathrm{Bb}$ and soluble $\mathrm{C} 5 \mathrm{~b}-9$ fragments. This suggests complement activation in the context of shigatoxinassociated hemolytic uremic syndrome. Levels returned to normal 28 days after hospital discharge. Stahl et al ${ }^{58}$ reported C3 deposition on platelets from patients with shigatoxininduced hemolytic uremic syndrome. They also examined platelet-derived and monocyte-derived microparticles from 12 patients with the syndrome and identified C3 and C9 deposits, suggesting complement activation. This group also incubated whole blood from normal controls with shigatoxin in the presence and absence of lipopolysaccharide. They found an increase in $\mathrm{C} 3$ and $\mathrm{C} 9$ which was greater with combined incubation.

Fang et $\mathrm{l}^{59}$ reported a fatal case of shigatoxin-induced hemolytic uremic syndrome which was associated with a heterozygous mutation in CD46/membrane cofactor protein. This A304V mutation affected the transmembrane domain, resulting in reduced regulatory activity when CD46 was membrane-bound. The same mutation was also found in a heterozygous form in other patients, including two children with atypical hemolytic uremic syndrome and one adult who had atypical hemolytic uremic syndrome/thrombotic thrombocytopenic purpura. Thus, this may represent a case of atypical hemolytic uremic syndrome with a shigatoxin infection trigger. However, it may signify a link between complement dysregulation and the pathogenesis of shigatoxin-associated hemolytic uremic syndrome.

\section{Antibiotics}

The role of antibiotics in the prevention of hemolytic uremic syndrome has been an area of intense speculation and debate. A summary of the relevant patient studies is shown in Table 1. Most studies are cohort series of varying sizes, with only one randomized, controlled trial by Proulx et a ${ }^{64}$ which did not show any difference with treatment using cotrimoxazole (relative risk 0.57, confidence interval [CI] 0.09-3.46, $P=0.67)$. However, the numbers enrolled were small, and mean time to administration of antibiotics was delayed until 7 days from onset of symptoms. Because hemolytic uremic syndrome mainly develops at days $5-7$, the timing of antibiotic therapy may have been too late. The majority of the other published studies also did not show any difference in risk of hemolytic uremic syndrome with antibiotics. ${ }^{65-70}$ In these studies, antibiotics were administered early within 3 days. However, these studies were mainly retrospective in nature and included a small number of patients.

There has been only one study reporting a benefit in reducing hemolytic uremic syndrome cases with antibiotics. This was a prospective study in an outbreak involving schoolchildren in Sakai, Japan. ${ }^{71}$ the children were treated early following Ministry of Health advice and $83 \%$ had antibiotics within 3 days, with $88 \%$ being treated with fosfomycin. Analysis of the fosfomycin group showed a reduced risk if antibiotics were given within 2 days in a multivariate analysis controlled for severity (odds ratio [OR] 0.15, CI 0.03-0.78). Nevertheless, the benefit was lost if the analysis included antibiotics started after 3 days. Caution has to be exercised when interpreting results from subanalyses. In an in vitro study, fosfomycin increased production of shigatoxin 1, although a cytotoxicity assay of cell lines showed only a small increase in biological activity. ${ }^{72}$ Conversely, fosfomycin therapy in malnourished mice reduced fecal shedding and shigatoxin numbers. ${ }^{73}$ More recent in vitro studies also showed that fosfomycin did not induce expression of shigatoxin. ${ }^{74,75}$

The evidence also shows that antibiotics can increase the risk of hemolytic uremic syndrome. In one of the earlier studies, six of eight patients treated with cotrimoxazole or sulfonamides developed hemolytic uremic syndrome in an outbreak at a training center and home for the learning disabled, compared with none of the remaining 18 verotoxigenic E. coli (VTEC)-infected patients. ${ }^{76}$ This could be due to more unwell patients being targeted with antibiotics. In a multicenter, prospective, cohort study in Washington, Oregon, Idaho, and Wyoming of mandatory reported cases of VTEC, antibiotics was a major risk factor for hemolytic uremic syndrome (relative risk 32.3, CI 1.4-737, $P=0.03$ ). ${ }^{77}$ There was no difference in characteristics or disease severity between the groups. The most common antibiotics administered were cotrimoxazole, cephalosporins, and amoxicillin. In the most recent published paper, from Minnesota, 63 hemolytic uremic syndrome cases and 125 VTEC controls were collected via central population-based surveillance by the Minnesota Department of Health. ${ }^{78}$ The risk of hemolytic uremic syndrome was analyzed by antibiotic class, ie, bactericidal agents (beta-lactams, quinolones, aminoglycosides, nitroimida- 


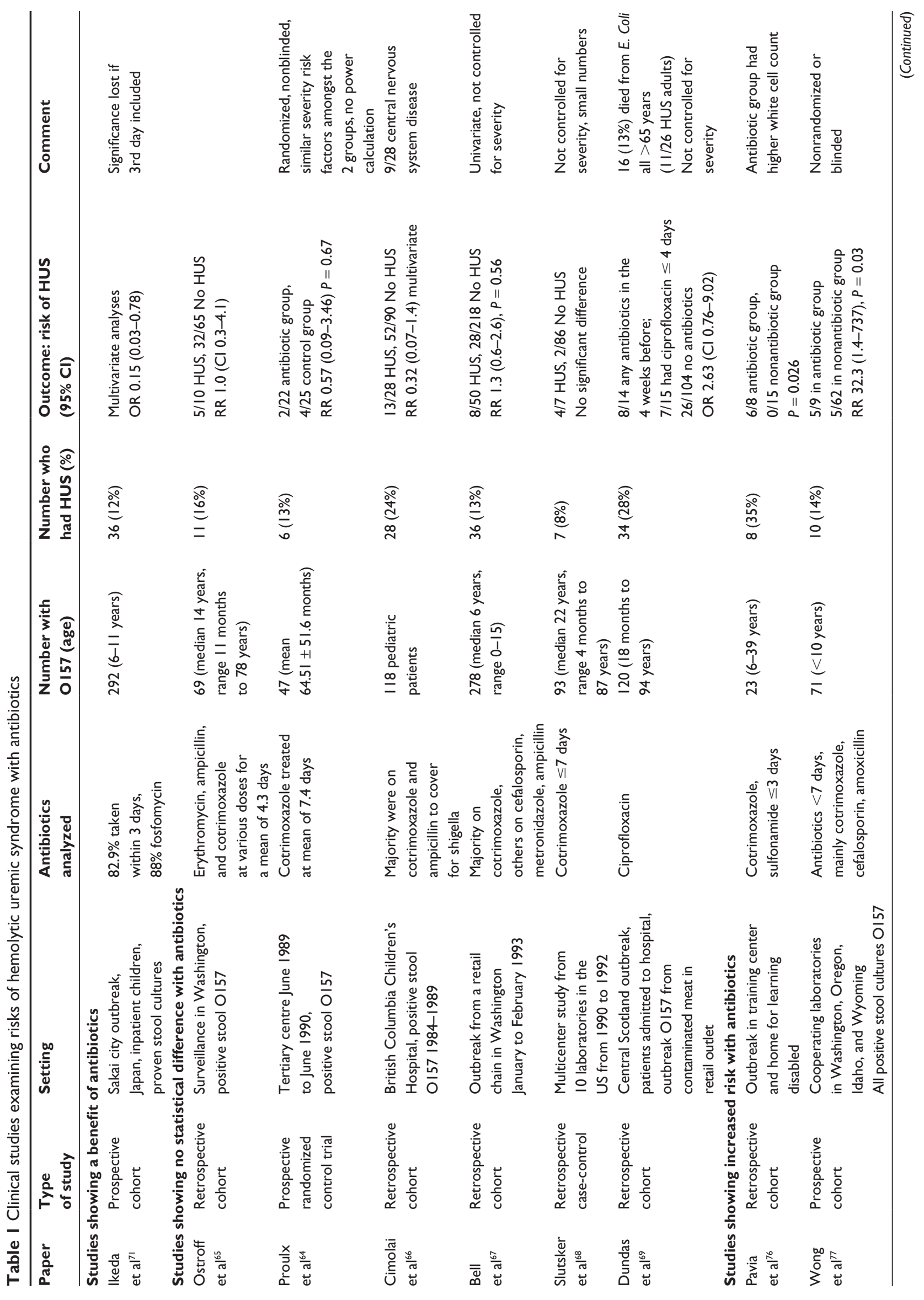




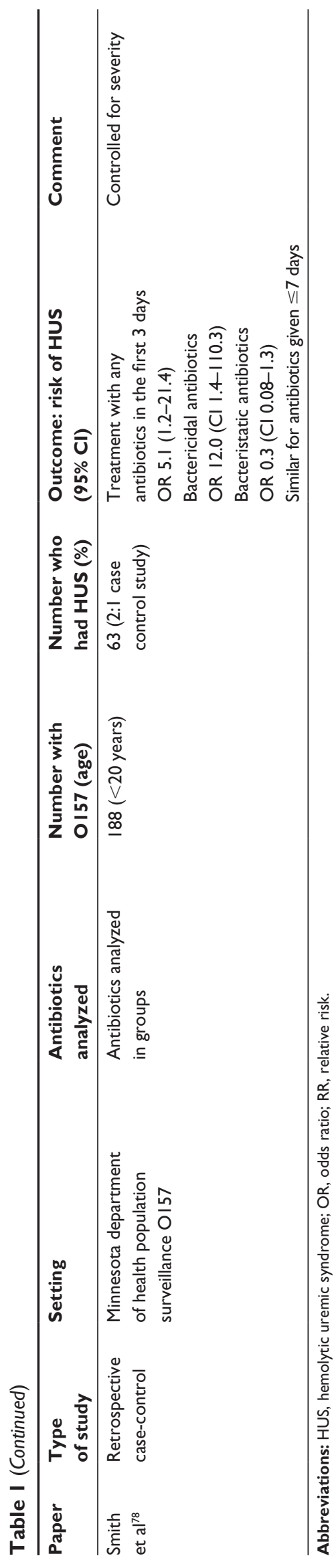

zoles) and bacteriostatic agents (sulfonamides, macrolides). A multivariate regression model was used with correction for identified confounding variables, ie, vomiting, fever, and bloody diarrhea. Patients who received bactericidal agents within 3 days had an increased risk of hemolytic uremic syndrome (OR 5.1, CI 1.2-21.4, $P=0.03$ ). Use of bacteriostatic antibiotics did not show any significant difference (OR $0.3,0.08-1.3, P=0.12$ ). The risks remained the same when analyzed for antibiotics given within 7 days.

The increased risk with bactericidal antibiotics is due to the release of shigatoxin. Quinolones induce production of shigatoxin dramatically by stimulating the SOS response of VTEC and by induction of coexpressed shigatoxin genes on bacteriophages. ${ }^{74,79,80}$ Shigatoxin is also rapidly released secondary to bacteriolysis. This effect is also demonstrable for other bactericidal antibiotics, though to a lesser extent. One study of 13 antibiotics and three 0157 strains showed that the response of shigatoxin expression was strain-specific, although all antibiotics increased shigatoxin expression in at least one HO157 strain. ${ }^{81}$ This may in part explain the conflicting findings in the literature. However, the bacteriostatic antibiotics have no effect on shigatoxin production, but in one study were able to suppress the release of shigatoxin in in vitro cocultures. ${ }^{82,83}$

Studies of antibiotics in VTEC are heterogenous. The effects of antibiotics are dependent on the VTEC strain and type of antibiotic. There is enough evidence showing harm with bactericidal antibiotics, and quinolones in particular can induce shigatoxin expression. Conversely, treatment with fosfomycin, macrolides, and newer-generation carbapenems do not cause upregulation of shigatoxin. Whether this would translate into therapy effective for preventing hemolytic uremic syndrome will require further randomized control trials. Currently though, routine use of antibiotics cannot be recommended.

\section{Plasma exchange}

Another cause of thrombotic microangiopathy which has to be differentiated from VTEC-induced hemolytic uremic syndrome is thrombotic thrombocytopenic purpura. The diagnosis of thrombotic thrombocytopenic purpura was traditionally used for adults with a diagnosis of thrombotic microangiopathy without renal involvement, as reviewed by George. ${ }^{84}$ It is now known to be caused by von Willebrand factor deficiency, secondary to ADAMTS13 deficiency, which leads to formation of large von Willebrand factor multimers. Thrombotic thrombocytopenic purpura is a clear indication for plasma exchange, with $80 \%$ of treated patients 
now surviving their acute episode. ${ }^{84}$ In thrombotic thrombocytopenic purpura, plasma exchange functions to remove prothrombotic factors and replace them with functional von Willebrand factor. Plasma exchange is also effective in atypical forms of hemolytic uremic syndrome, which are due to mutations in complement regulatory function. ${ }^{85,86}$ However, the use of plasma exchange in VTEC-induced hemolytic uremic syndrome is less evidence-based.

Plasma infusions have been studied in two multicenter, randomized, controlled studies in children with hemolytic uremic syndrome in Italy and France. ${ }^{87,88}$ These studies were conducted in the early 1980s just before shigatoxin was established as a cause of hemolytic uremic syndrome. Microbiological diagnosis of VTEC was not available and not all patients had diarrheal prodrome. The results should be interpreted cautiously because all these patients may not have had shigatoxin-hemolytic uremic syndrome. In addition, focal $\mathrm{C} 3$ was detected on glomerular loops in three patients in the Italian study, suggestive of C3 glomerulopathy, which would respond differently to plasma treatment. Plasma infusions of $10 \mathrm{~mL} / \mathrm{kg}$ day (first infusion of $30 \mathrm{~mL} /$ $\mathrm{kg}$ in the Italian study) were given early in the course of the disease and all within 8 days of first symptoms. There was no difference in the measured outcomes, including serum creatinine and proteinuria at the end of follow-up (12 months and 16 months in the French and Italian study, respectively). There was also no difference in histological score in the Italian study, but control group patients in the French study developed more cortical necrosis. Plasma infusions were not without risk, given that one patient developed fluid overload and two patients developed hepatitis in the Italian study. Overall outcomes in both studies were good, with all survivors coming off dialysis. This highlights the importance of thorough supportive therapy.

Plasma exchange has been described in two case series in adults with VTEC infection. In the 1996 central Scotland outbreak, plasma exchange was considered in all patients with hemolytic uremic syndrome and started within 24 hours of diagnosis. ${ }^{89}$ Hemolytic uremic syndrome developed in 22 patients, of whom 16 were treated with plasma exchange. Fresh frozen plasma replacement was used in all patients, except one, who was switched to cryosupernatant due to a refractory clinical response. Hydrocortisone and prostacyclin were also given at each plasma exchange session. In this case series, mortality was $31 \%(5 / 16)$, which the authors compared with a historical mortality rate of $80 \%$. Without a control group, it is not known if the outcome would have been the same without treatment.
The second case series was described in the recent Northern European E. coli O104:H4 outbreak. ${ }^{90}$ A small case series of five previously healthy patients of median age 62 (range 44-70) years was published from Denmark. Patients were treated with one volume of plasma exchange using fresh frozen plasma replacement, and plasma exchange was started 3-9 days from the onset of bloody diarrhea. Markers of hemolysis and glomerular filtration rate improved after the start of plasma exchange, and none of these patients required dialysis. However, without controls, one cannot be certain if the improvement was due to plasma exchange or was simply part of the natural history of the disease. In fact, the results were already showing an improving trend before the start of plasma exchange. In the same outbreak, a group of patients with severe neurological symptoms requiring intensive care management who had not responded to plasma exchange and eculizumab were also treated with immunoadsorption. ${ }^{93}$ Immunoadsorption achieves $85 \%$ removal of IgG compared with $40 \%$ in plasma exchange. ${ }^{92,93}$ Using a newly designed central nervous system score, the investigators showed that the neurological status of the patients improved following immunoadsorption, and even described the improvement as occurring "right before their eyes".

The biological mechanism behind plasma exchange is not known. It is postulated to remove proinflammatory and prothrombotic factors (as described above) or shigatoxinbound antibodies. However, the passage of shigatoxin in patients is still not known, although it has been shown to bind platelets and leukocytes. Cell-bound shigatoxin would not be removed by plasma exchange.

\section{Shigatoxin-neutralizing strategies}

Neutralizing shigatoxin is an attractive strategy for reducing the risk of developing hemolytic uremic syndrome. Nevertheless, efforts so far have not translated into successful treatment in patients. ${ }^{94}$ This is partly due to a narrow therapeutic window of opportunity. VTEC reaches maximum numbers in the gut when initial gastrointestinal symptoms appear, causing patients to present to their doctors. ${ }^{95}$ There is a further delay in confirming the diagnosis via current stool culture methods. Modern diagnostic tools, such as the shigatoxin polymerase chain reaction, are typically not available at the point of demand, and limited to research facilities or retrospective confirmation of cases. Once the diagnosis is confirmed, typically 48 hours later, shigatoxin would have circulated in the bloodstream..$^{92}$ Effects of vascular activation have been detected as early as 4 days after the onset of diarrhea. ${ }^{96}$ Therefore, for maximum efficacy, 
treatment needs to be started as early as possible, ideally within 2 days of diarrhea, so rapid bedside diagnostic tools need to be developed.

The second hurdle in the development of a shigatoxinneutralizing agent is production of an agent which has a higher affinity for shigatoxin than its receptor. The agent also needs to be effective for shigatoxin 1 and shigatoxin $2 .{ }^{97}$ Synsorb-Pk was one of the early shigatoxin-binding molecules which reached Phase II trials in patients. Unfortunately, it did not reduce the severity of hemolytic uremic syndrome or prevent dialysis when given after diagnosis of the syndrome. ${ }^{98}$ Treatment of children with shigatoxigenic E. coli or household contacts was also inconclusive and this drug has now been abandoned. ${ }^{99}$ Further higher-affinity molecules have been developed using Gb3 trisaccharide polymers. These have been named Super Twig, Starfish, and Daisy, reflecting their molecular structure, ${ }^{100-102}$ and have the drawback of requiring parenteral or subcutaneous administration. These multivalent ligands have been effective in animal models, but have not found their way into human studies. ${ }^{100-102}$ Treatment in animals was usually given concomitantly with shigatoxin inoculation or very soon after, and is therefore not translatable to patient care. In another development, urtoxazumab, a humanized monoclonal antibody towards shigatoxin 2 , has been shown to be safe in patients, but has not yet been subjected to clinical trials. ${ }^{103}$

Shigatoxin binding by multivalent ligands leads to clearance via the reticuloendothelial system. More recently, a cell-permeable peptide with shigatoxin 2-binding properties (PPP-tet) was developed. ${ }^{104}$ This molecule had the additional benefit of inhibiting the cytosolic transport of shigatoxin to the endoplasmic reticulum and diverting shigatoxin to lysosomal degradation. Due to the cell-permeable nature of PPP-tet, it could potentially be effective even after binding of shigatoxin to the cell membrane and could have a wider therapeutic window in patients. ${ }^{104}$ This treatment rescued mice from lethal shigatoxigenic $E$. coli challenge when given orally at 3 days. ${ }^{104}$ In a primate animal model, PPP-tet also ameliorated kidney injury when given 24 hours after shigatoxin. ${ }^{105}$

\section{VEGF-A}

VEGF is another source of research interest. VEGFs are a group of proteins which includes placental-derived growth factor, VEGF-A, VEGF-B, VEGF-C, and VEGF-D. ${ }^{106,107}$ VEGF$A$ is particularly well studied and has an important role in angiogenesis, vasculogenesis, and the maintenance of a healthy endothelium. It is secreted by perivascular epithelial cells.
In the glomerulus, this is the podocyte. ${ }^{104}$ The role of VEGF in the development of glomerular thrombotic microangiopathy became apparent when patients treated with anti-VEGF agents for cancer developed glomerular thrombotic microangiopathy and features of hemolytic uremic syndrome as an unexpected side effect. This was studied further by Eremina et $\mathrm{al}^{43}$ who developed a podocyte-specific inducible VEGF-A knockdown mouse. Adult mice had podocyte VEGF secretion switched off and developed thrombotic microangiopathy. This showed the vital crosstalk involved between podocytes and glomerular endothelial cells in the maintenance of the glomerular filtration barrier and also revealed a new mechanism for the development of glomerular thrombotic microangiopathy, which is interesting because shigatoxin-treated mice do not develop glomerular thrombotic microangiopathy. We currently do not understand why reduced VEGF-A causes thrombotic microangiopathy. The role of VEGF-A in the pathogenesis of shigatoxin-associated hemolytic uremic syndrome requires further study, but Psotka et $\mathrm{al}^{20}$ showed that human podocytes in culture showed reduced VEGF-A secretion after treatment with shigatoxin 2 .

\section{Complement inhibitors and eculizumab}

In a letter to the New England Journal of Medicine in 2011, Lapeyraque et $\mathrm{al}^{60}$ described three pediatric patients with severe shigatoxin hemolytic uremic syndrome who received eculizumab. All were 3 years old and had evidence of complement activation on blood tests (low $\mathrm{C} 3$ and high $\mathrm{C} 3 \mathrm{~d}$ ) and severe neurological involvement. Two received 5-7 sessions of plasma exchange prior to receiving eculizumab. All had renal involvement requiring hemodialysis. Patient 1 received two doses of eculizumab 10 days after initial management was started. Patient 2 received four doses which started 5 days after the start of initial management. Patient 3 received two doses which started on day 7 of initial management. In all patients, there was improvement in neurological status. Sequential magnetic resonance imaging was performed in one patient which showed resolution of leucoencephalopathic changes. Lactate dehydrogenase reduced and platelet count increased 7-12 days after treatment with eculizumab. These results should be interpreted with caution because they may reflect the natural disease course rather than eculizumab therapy, given that patients with $E$. coli-associated hemolytic uremic syndrome often recover up to 4 weeks after disease onset.

In May 2011, there was a large outbreak of E. coliassociated hemolytic uremic syndrome in northern Germany. ${ }^{8}$ This outbreak was unusual in that it affected 
predominantly adults. The causative organism was not $E$. coli $\mathrm{O} 157$ but $E$. coli $\mathrm{O} 104: \mathrm{H} 4$, an enteroaggregative bacteria which had acquired a prophage-encoding shigatoxin. ${ }^{61}$ More than 3000 people were infected and approximately 50 people died, including 36 from hemolytic uremic syndrome. ${ }^{8}$ This outbreak served as a platform for an impromptu drug trial of eculizumab in D+HUS. ${ }^{62,63}$ An initial report on the results of the German study was reported at the American Society of Nephrology, Philadelphia, PA, in November 2011. In total, 196 patients from nine German centers were treated with more than one dose of eculizumab. Patients were on the severe end of the spectrum, with the majority having severe cerebral and renal involvement requiring renal replacement. Eighty-seven percent of those who received eculizumab had had plasma exchange prior to treatment. The majority of patients received eculizumab at a median 11 days into their diarrheal illness. After 8 weeks of treatment, $95 \%$ of patients showed a partial or complete improvement of hematological parameters and neurological complications. Fifty-six percent had normal renal function whilst 36\% remained dialysisdependent. Full results are awaited, and these findings should be interpreted with caution because there were multiple concomitant treatments and no control group. Therefore, whilst there may be evidence of complement involvement in D+HUS, use of eculizumab for treatment of this disease is not yet established. Drugs targeting other proinflammatory components of the complement cascade could also be potential future therapeutic options.

\section{Summary}

$\mathrm{D}+\mathrm{HUS}$ is an important disease entity that carries significant morbidity and mortality. Currently, our incomplete understanding of the pathogenic mechanisms is impacting on the available treatments. Routine use of antibiotics other than fosfomycin is not recommended because it can exacerbate the disease. Plasma exchange and immunoadsorption have been used in patients with severe disease and cerebral manifestations based on anecdotal case series. Potential future therapies include cell-permeable peptides for shigatoxinbinding and complement inhibitors such as eculizumab to ameliorate disease.

\section{Disclosure}

The authors report no conflicts of interest in this work.

\section{References}

1. Scheiring J, Andreoli SP, Zimmerhackl LB. Treatment and outcome of Shiga-toxin-associated hemolytic uremic syndrome (HUS). Pediatr Nephrol. 2008;23:1749-1760.
2. Garg AX, Suri RS, Barrowman N, et al. Long-term renal prognosis of diarrhea-associated hemolytic uremic syndrome: a systematic review, meta-analysis, and meta-regression. JAMA. 2003;290:1360-1370.

3. Ake JA, Jelacic S, Ciol MA, et al. Relative nephroprotection during Escherichia coli O157:H7 infections: association with intravenous volume expansion. Pediatrics. 2005;115:e673-e680.

4. Verweyen HM, Karch H, Brandis M, Zimmerhack1 LB. Enterohemorrhagic Escherichia coli infections: following transmission routes. Pediatr Nephrol. 2000;14:73-83.

5. Noris M, Remuzzi G. Hemolytic uremic syndrome. J Am Soc Nephrol. 2005;16:1035-1050.

6. Taylor CM. Enterohaemorrhagic Escherichia coli and Shigella dysenteriae type 1-induced haemolytic uraemic syndrome. Pediatr Nephrol. 2008;23:1425-1431.

7. Lynn RM, O'Brien SJ, Taylor CM, et al. Childhood hemolytic uremic syndrome, United Kingdom and Ireland. Emerg Infect Dis. 2005; 11:590-596.

8. Frank C, Werber D, Cramer JP; for HUS Investigation Team. Epidemic profile of Shiga-toxin-producing Escherichia coli O104:H4 outbreak in Germany. N Engl J Med. 2011;365:1771-1780.

9. Gianviti A, Tozzi AE, De Petris L, et al. Risk factors for poor renal prognosis in children with hemolytic uremic syndrome. Pediatr Nephrol. 2003;18:1229-1235.

10. Nathanson S, Kwon T, Elmaleh M, et al. Acute neurological involvement in diarrhea-associated hemolytic uremic syndrome. Clin J Am Soc Nephrol. 2010;5:1218-1228.

11. Donnerstag F, Ding X, Pape L, et al. Patterns in early diffusionweighted MRI in children with haemolytic uraemic syndrome and CNS involvement. Eur Radiol. 2012;22:506-513.

12. Eriksson KJ, Boyd SG, Tasker RC. Acute neurology and neurophysiology of haemolytic-uraemic syndrome. Arch Dis Child. 2001;84:434-435.

13. Zoja C, Buelli S, Morigi M. Shiga toxin-associated hemolytic uremic syndrome: pathophysiology of endothelial dysfunction. Pediatr Nephrol. 2010;25:2231-2240.

14. Zumbrun SD, Hanson L, Sinclair JF, et al. Human intestinal tissue and cultured colonic cells contain globotriaosylceramide synthase mRNA and the alternate shiga toxin receptor globotetraosylceramide. Infect Immun. 2010;78:4488-4499.

15. Brigotti M, Tazzari PL, Ravanelli E, et al. Clinical relevance of shiga toxin concentrations in the blood of patients with hemolytic uremic syndrome. Pediatr Infect Dis J. 2011;30:486-490.

16. Schüller S. Shiga toxin interaction with human intestinal epithelium. Toxins. 2011;3:626-639.

17. GrienerTP, Mulvey GL, Marcato P, Armstrong GD. Differential binding of shiga toxin 2 to human and murine neutrophils. J Med Microbiol. 2007;56:1423-1430.

18. Ghosh SA, Polanowska-Grabowska RK, Fujii J, Obrig T, Gear AR. Shiga toxin binds to activated platelets. J Thromb Haemost. 2004;2:499-506.

19. Bitzan M, Richardson S, Huang C, Boyd B, Petric M, Karmali MA. Evidence that verotoxins (Shiga-like toxins) from Escherichia coli bind to $\mathrm{P}$ blood group antigens of human erythrocytes in vitro. Infect Immun. 1994;62:3337-3347.

20. Psotka MA, Obata F, Kolling GL, et al. Shiga toxin 2 targets the murine renal collecting duct epithelium. Infect Immun. 2009;77:959-969.

21. Ergonul Z, Hughes AK, Kohan DE. Induction of apoptosis of human brain microvascular endothelial cells by shiga toxin 1 . J Infect Dis. 2003;187:154-158.

22. Mattocks M, Bagovich M, De Rosa M, et al. Treatment of neutral glycosphingolipid lysosomal storage diseases via inhibition of the $\mathrm{ABC}$ drug transporter, MDR1. Cyclosporin A can lower serum and liver globotriaosyl ceramide levels in the Fabry mouse model. FEBSJ. 2006;273:2064-2075.

23. Johannes L, Römer W. Shiga toxins - from cell biology to biomedical applications. Nat Rev Microbiol. 2010;8:105-116.

24. Spooner RA, Lord JM. How ricin and Shiga toxin reach the cytosol of target cells: retrotranslocation from the endoplasmic reticulum. Curr Top Microbiol Immunol. 2012;357:19-40. 
25. Brigotti M, Alfieri R, Sestili P, et al. Damage to nuclear DNA induced by Shiga toxin 1 and ricin in human endothelial cells. FASEB $J$. 2002;16:365-372.

26. Zoja C, Angioletti S, Donadelli R, et al. Shiga toxin-2 triggers endothelial leukocyte adhesion and transmigration via NF-kappaB dependent up-regulation of IL-8 and MCP-1. Kidney Int. 2002;62:846-856.

27. Morigi M, Galbusera M, Binda E, et al. Verotoxin-1-induced upregulation of adhesive molecules renders microvascular endothelial cells thrombogenic at high shear stress. Blood. 2001;98: $1828-1835$

28. Müthing J, Schweppe CH, Karch H, Friedrich AW. Shiga toxins, glycosphingolipid diversity, and endothelial cell injury. Thromb Haemost. 2009;101:252-264.

29. Fraser ME, Fujinaga M, Cherney MM, et al. Structure of shiga toxin type 2 (Stx2) from Escherichia coli O157:H7. J Biol Chem. 2004;279:27511-27517.

30. Obrig TG, Louise CB, Lingwood CA, Boyd B, Barley-Maloney L, Daniel TO. Endothelial heterogeneity in Shiga toxin receptors and responses. J Biol Chem. 1993;268:15484-15488.

31. Bauwens A, Bielaszewska M, Kemper B, et al. Differential cytotoxic actions of Shiga toxin 1 and Shiga toxin 2 on microvascular and macrovascular endothelial cells. Thromb Haemost. 2011;105:515-528.

32. Mahfoud R, Manis A, Lingwood CA. Fatty acid-dependent globotriaosyl ceramide receptor function in detergent resistant model membranes. $J$ Lipid Res. 2009;50:1744-1755.

33. Khan F, Proulx F, Lingwood CA. Detergent-resistant globotriaosyl ceramide may define verotoxin/glomeruli-restricted hemolytic uremic syndrome pathology. Kidney Int. 2009;75:1209-1216.

34. Zheng XL, Sadler JE. Pathogenesis of thrombotic microangiopathies. Annu Rev Pathol. 2008;3:249-277.

35. Ruggenenti P, Noris M, Remuzzi G. Thrombotic microangiopathy, hemolytic uremic syndrome, and thrombotic thrombocytopenic purpura. Kidney Int. 2001;60:831-846.

36. Fernández GC, Te Loo MW, van der Velden TJ, van der Heuvel LP, Palermo MS, Monnens LL. Decrease of thrombomodulin contributes to the procoagulant state of endothelium in hemolytic uremic syndrome. Pediatr Nephrol. 2003;18:1066-1068.

37. Nolasco LH, Turner NA, Bernardo A, et al. Hemolytic uremic syndromeassociated Shiga toxins promote endothelial-cell secretion and impair ADAMTS13 cleavage of unusually large vonWillebrand factor multimers. Blood. 2005;106:4199-4209.

38. Murata K, Higuchi T, Takada K, Oida K, Horie S, Ishii H. Verotoxin-1stimulation of macrophage-like THP-1 cells upregulates tissue factor expression through activation of c-Yes tyrosine kinase: possible signal transduction in tissue factor upregulation. Biochim Biophys Acta. 2006;1762:835-843.

39. Hughes AK, Stricklett PK, Schmid D, Kohan DE. Cytotoxic effect of Shiga toxin-1 on human glomerular epithelial cells. Kidney Int. 2000;57:2350-2359.

40. De Petris L, Patrick J, Christen E, Trachtman H. Urinary podocyte mRNA excretion in children with D+HUS: a potential marker of longterm outcome. Ren Fail. 2006;28:475-482.

41. Hughes AK, Stricklett PK, Kohan DE. Cytotoxic effect of Shiga toxin-1 on human proximal tubule cells. Kidney Int. 1998;54:426-437.

42. Kavanagh D, Goodship T. Genetics and complement in atypical HUS. Pediatr Nephrol. 2010;25:2431-2442.

43. Eremina V, Jefferson JA, Kowalewska J, et al. VEGF inhibition and renal thrombotic microangiopathy. N Engl J Med. 2008;358:1129-1136.

44. Roumenina LT, Loirat C, Dragon-Durey MA, Halbwachs-Mecarelli L, Sautes-Fridman C, Fremeaux-Bacchi V.Alternative complement pathway assessment in patients with atypical HUS. J Immunol Methods. 2011;365:8-26.

45. Warwicker P, Goodship TH, Donne RL, et al. Genetic studies into inherited and sporadic hemolytic uremic syndrome. Kidney Int. 1998;53:836-844.

46. Fremeaux-Bacchi V, Dragon-Durey MA, Blouin J, et al. Complement factor I: a susceptibility gene for atypical haemolytic uraemic syndrome. J Med Genet. 2004;41:e84.
47. Richards A, Kemp EJ, Liszewski MK, et al. Mutations in human complement regulator, membrane cofactor protein (CD46), predispose to development of familial hemolytic uremic syndrome. Proc Natl Acad Sci U S A. 2003;100:12966-12971.

48. Goicoechea de Jorge E, Harris CL, Esparza-Gordillo J, et al. Gain-of-function mutations in complement factor B are associated with atypical hemolytic uremic syndrome. Proc Natl Acad Sci. 2007;104: 240-245.

49. Fremeaux-Bacchi V, Miller EC, Liszewski MK, et al. Mutations in complement $\mathrm{C} 3$ predispose to development of atypical hemolytic uremic syndrome. Blood. 2008;112:4948-4952.

50. Delvaeye M, Noris M, De Vriese A, et al. Thrombomodulin mutations in atypical hemolytic-uremic syndrome. $N$ Engl J Med. 2009;361:345-357.

51. Noris M, Remuzzi G. Atypical hemolytic-uremic syndrome. $N$ Engl $J$ Med. 2009;361:1676-1687.

52. Jokiranta TS, Zipfel PF, Fremeaux-Bacchi V, Taylor CM, Goodship TJ, Noris M. Where next with atypical haemolytic uremic syndrome? Mol Immunol. 2007;44:3889-3900.

53. Robson WL, Leung AK, Fick GH, McKenna AI. Hypocomplementemia and leukocytosis in diarrhea-associated hemolytic uremic syndrome. Nephron. 1992;62:296-299.

54. Monnens L, Molenaar J, Lambert PH, Proesmans W, van Munster P. The complement system in hemolytic-uremic syndrome in childhood. Clin Nephrol. 1980;13:168-171.

55. Thurman JM, Marians R, Emlen W, et al. Alternative pathway of complement in children with diarrhea-associated hemolytic uremic syndrome. Clin J Am Soc Nephrol. 2009;4:1920-1924.

56. Orth $\mathrm{D}$, Khan AB, Naim A, et al. Shiga toxin activates complement and binds factor $\mathrm{H}$ : evidence for an active role of complement in hemolytic uremic syndrome. J Immunol. 2009;182:6394-6400.

57. Morigi M, Galbusera M, Gastoldi S, et al. Alternative pathway activation of complement by Shiga toxin promotes exuberant C3a formation that triggers microvascular thrombosis. J Immunol. 2011;187:172-180.

58. StåhlAL, Sartz L, Karpman D. Complement activation on platelet-leukocyte complexes and microparticles in enterohemorrhagic Escherichia coliinduced hemolytic uremic syndrome. Blood. 2011;117:5503-5513.

59. Fang CJ, Fremeaux-Bacchi V, Liszewski MK, et al. Membrane cofactor protein mutations in atypical hemolytic uremic syndrome (aHUS), fatal Stx-HUS, C3 glomerulonephritis, and the HELLP syndrome. Blood. 2008;111:624-632.

60. Lapeyraque AL, Malina M, Fremeaux-Bacchi V, et al. Eculizumab in severe Shiga-toxin-associated HUS. $N$ Engl J Med. 2011;364: 2561-2563.

61. Rasko DA, Webster DR, Sahl JW, et al. Origins of the E. coli strain causing an outbreak of hemolytic-uremic syndrome in Germany. N Engl J Med. 2011;365:709-717.

62. Nitschke M, Sayk F, Härtel C, et al. Association between azithromycin therapy and duration of bacterial shedding among patients with Shiga toxin-producing enteroaggregative Escherichia coli O104:H4. JAMA. 2012;307:1046-1052.

63. Turner M. German E. coli outbreak leads to drug trial. Available from: http://www.nature.com/news/2011/110527/full/news.2011.332.html. Accessed May 26, 2012.

64. Proulx F, Turgeon JP, Delage G, Lafleur L, Chicoine L. Randomized, controlled trial of antibiotic therapy for Escherichia coli O157: H7 enteritis. J Pediatr. 1992;121:299-303.

65. Ostroff SM, Kobayashi JM, Lewis JH. Infections with Escherichia coli O157:H7 in Washington State. The first year of statewide disease surveillance. JAMA. 1989;262:355-359.

66. Cimolai N, Basalyga S, Mah DG, Morrison BJ, Carter JE. A continuing assessment of risk factors for the development of Escherichia coli O157:H7-associated hemolytic uremic syndrome. Clin Nephrol. 1994;42:85-89.

67. Bell BP, Griffin PM, Lozano P, Christie DL, Kobayashi JM, Tarr PI. Predictors of hemolytic uremic syndrome in children during a large outbreak of Escherichia coli O157:H7 infections. Pediatrics. 1997;100:E12. 
68. Slutsker L, Ries AA, Maloney K, Wells JG, Greene KD, Griffin PM. A nationwide case-control study of Escherichia coli O157:H7 infection in the United States. J Infect Dis. 1998;177:962-966.

69. Dundas S, Todd WT, Stewart AI, Murdoch PS, Chaudhuri AK, Hutchinson SJ. The central Scotland Escherichia coli O157:H7 outbreak: risk factors for the hemolytic uremic syndrome and death among hospitalized patients. Clin Infect Dis. 2001;33:923-931.

70. Michael M, Elliott EJ, Ridley GF, Hodson EM, Craig JC. Interventions for haemolytic uraemic syndrome and thrombotic thrombocytopenic purpura. Cochrane Database Syst Rev. 2009;1:CD003595.

71. Ikeda K, Ida O, Kimoto K, Takatorige T, Nakanishi N, Tatara K. Effect of early fosfomycin treatment on prevention of hemolytic uremic syndrome accompanying Escherichia coli O157:H7 infection. Clin Nephrol. 1999;52:357-362.

72. Yoh M, Frimpong EK, Honda T. Effect of antimicrobial agents, especially fosfomycin, on the production and release of Vero toxin by enterohaemorrhagic Escherichia coli O157:H7. FEMS Immunol Med Microbiol. 1997;19:57-64.

73. Kurioka T, Yunou Y, Harada H, Kita E. Efficacy of antibiotic therapy for infection with Shiga-like toxin producing Escherichia coli O157:H7 in mice with protein-calorie malnutrition. Eur J Clin Microbiol Infect Dis. 1999;18:561-571.

74. Zhang X, McDaniel AD, Wolf LE, et al. Quinolone antibiotics induce Shiga toxin-encoding bacteriophages, toxin production, and death in mice. J Infect Dis. 2000;181:664-670.

75. Ichinohe N, Ohara-Nemoto Y, Nemoto TK, Kimura S, Ichinohe S. Effects of fosfomycin on Shiga toxin-producing Escherichia coli: quantification of copy numbers of Shiga toxin-encoding genes and their expression levels using real-time PCR. J Med Microbiol. 2009;58:971-973.

76. Pavia AT, Nichols CR, Green DP, et al. Hemolytic-uremic syndrome during an outbreak of Escherichia coli O157:H7 infections in institutions for mentally retarded persons: clinical and epidemiologic observations. J Pediatr. 1990;116:544-551.

77. Wong CS, Jelacic S, Habeeb RL, Watkins SL, Tarr PI. The risk of the hemolytic-uremic syndrome after antibiotic treatment of Escherichia coli O157:H7 infections. N Engl J Med. 2000;342:1930-1936.

78. Smith KE, Wilker PR, Reiter PL, Hedican EB, Bender JB, Hedberg CW. Antibiotic treatment of Escherichia coli $\mathrm{O} 157$ infection and the risk of hemolytic uremic syndrome, Minnesota. Pediatr Infect Dis J. 2012;31:37-41.

79. Kimmitt PT, Harwood CR, Barer MR. Induction of type 2 Shiga toxin synthesis in Escherichia coli $\mathrm{O} 157$ by 4-quinolones. Lancet. 1999;353:1588-1589.

80. Kimmitt P, Harwood C, Barer M. Toxin gene expression by Shiga toxin producing Escherichia coli: the role of antibiotics and the bacterial SOS response. Emerg Infect Dis. 2000;6:458-465.

81. Grif K, Dierich MP, Karch H, Allerberger F. Strain specific differences in the amount of Shiga toxin released from enterohemorrhagic Escherichia coli O157 following exposure to subinhibitory concentrations of antimicrobial agents. Eur J Clin Microbiol Infect Dis. 1998;17:761-766.

82. Murakami J, Kishi K, Hirai K, Hiramatsu K, Yamasaki T, Nasu M. Macrolides and clindamycin suppress the release of Shiga-like toxins from Escherichia coli O157:H7 in vitro. Int J Antimicrob Agents. 2000;15:103-109.

83. Ochoa TJ, Chen J, Walker CM, Gonzales E, Cleary TG. Rifaximin does not induce toxin production or phage-mediated lysis of Shiga toxin-producing Escherichia coli. Antimicrob Agents Chemother 2007;51:2837-2841.

84. George JN. How I treat patients with thrombotic thrombocytopenic purpura: 2010. Blood. 2010;116:4060-4069.

85. Waters AM, Licht C. Atypical HUS caused by complement dysregulation: new therapies on the horizon. Pediatr Nephrol. 2011;26:41-57.

86. Kim JJ, Goodship TH, Tizard J, Inward C. Plasma therapy for atypical haemolytic uraemic syndrome associated with heterozygous factor $\mathrm{H}$ mutations. Pediatr Nephrol. 2011;26:2073-2076.

87. Loirat C, Sonsino E, Hinglais N, Jais JP, Landais P, Fermanian J. Treatment of the childhood haemolytic uraemic syndrome with plasma. A multicentre randomized controlled trial. The French Society of Paediatric Nephrology. Pediatr Nephrol. 1988;2:279-285.
88. Rizzoni G, Claris-Appiani A, Edefonti A, et al. Plasma infusion for hemolytic-uremic syndrome in children: results of a multicenter controlled trial. J Pediatr. 1988;112:284-290.

89. Dundas S, Murphy J, Soutar RL, Jones GA, Hutchinson SJ, Todd WT. Effectiveness of therapeutic plasma exchange in the 1996 Lanarkshire Escherichia coli O157:H7 outbreak. Lancet. 1999;354:1327-1330.

90. Colic E, Dieperink H, Titlestad K, Tepel M. Management of an acute outbreak of diarrhoea-associated haemolytic uraemic syndrome with early plasma exchange in adults from southern Denmark: an observational study. Lancet. 2011;378:1089-1093.

91. Greinacher A, Friesecke S, Abel P, et al. Treatment of severe neurological deficits with $\mathrm{IgG}$ depletion through immunoadsorption in patients with Escherichia coli O104:H4-associated haemolytic uraemic syndrome: a prospective trial. Lancet. 2011;378:1166-1173.

92. Staudt A, Böhm M, Knebel F, et al. Potential role of autoantibodies belonging to the immunoglobulin G-3 subclass in cardiac dysfunction among patients with dilated cardiomyopathy. Circulation. 2002;106:2448-2453.

93. Ward DM. Conventional apheresis therapies: a review. J Clin Apher. 2011;26:230-238.

94. Karmali MA. Prospects for preventing serious systemic toxemic complications of Shiga toxin-producing Escherichia coli infections using Shiga toxin receptor analogues. J Infect Dis. 2004;189:355-359.

95. Tarr PI, Neill MA, Clausen CR, Watkins SL, Christie DL, Hickman RO. Escherichia coli O157:H7 and the hemolytic uremic syndrome: importance of early cultures in establishing the etiology. J Infect Dis. 1990;162:553-556

96. Tarr PI. Basic fibroblast growth factor and Shiga toxin-O157:H7-associated hemolytic uremic syndrome. J Am Soc Nephrol. 2002;13:817-820.

97. Nishikawa K. Recent progress of Shiga toxin neutralizer for treatment of infections by Shiga toxin-producing Escherichia coli. Arch Immunol Ther Exp. 2011;59:239-247.

98. Trachtman H, Cnaan A, Christen E, et al. Effect of an oral Shiga toxinbinding agent on diarrhea-associated hemolytic uremic syndrome in children: a randomized controlled trial. JAMA. 2003;290:1337-1344.

99. Armstrong GD, McLaine PN, Rowe PC. Clinical trials of synsorb Pk in preventing hemolytic uremic syndrome. In: Kaper JB, O'Brien AD, editors. Escherichia coli O157:H and Other Shiga Toxin-producing E. coli Strains. Washington, DC: American Society for Microbiology Press; 1998.

100. Nishikawa K, Koji M, Kita E, et al. A therapeutic agent with oriented carbohydrates for treatment of infections by Shiga toxin-producing Escherichia coli O157:H7. Proc Natl Acad Sci U SA. 2002;99:7669-7674.

101. Kitov PI, Sadowska JM, Mulvey G, et al. Shiga like toxins are neutralized by tailored multivalent carbohydrate ligands. Nature. 2000;403:669-672.

102. Mulvey G, Marcato P, Kitov P, Sadowska JM, Bundle DR, Armstrong GD. Assessment in mice of the therapeutic potential of tailored, multivalent Shiga toxin carbohydrate ligands. J Infect Dis. 2003;187:640-669.

103. López EL, Contrini MM, Glatstein E, et al. Safety and pharmacokinetics of urtoxazumab, a humanized monoclonal antibody, against Shiga-like toxin 2 in healthy adults and in pediatric patients infected with Shiga-like toxin-producing Escherichia coli. Antimicrob Agents Chemother. 2010;54:239-243.

104. Nishikawa K, Watanabe M, Kita E, et al. A multivalent peptide library approach identifies a novel Shiga toxin inhibitor that induces aberrant cellular transport of the toxin. FASEB J. 2006;20:2597-2599.

105. Stearns-Kurosawa DJ, Collins V, Freeman S, et al. Rescue from lethal Shiga toxin 2-induced renal failure with a cell-permeable peptide. Pediatr Nephrol. 2011;26:2031-2039.

106. Foster RR. The importance of cellular VEGF bioactivity in the development of glomerular disease. Nephron Exp Nephrol. 2009;113:e8-e15.

107. Eremina V, Baelde HJ, Quaggin SE. Role of the VEGF-A signaling pathway in the glomerulus: evidence for crosstalk between components of the glomerular filtration barrier. Nephron Physiol. 2007;106:32-37.

108. Keir L, Coward RJ. Advances in our understanding of the pathogenesis of glomerular thrombotic microangiopathy. Pediatr Nephrol. 2011;26(4):523-33. 


\section{Publish your work in this journal}

Drug Design, Development and Therapy is an international, peerreviewed open-access journal that spans the spectrum of drug design and development through to clinical applications. Clinical outcomes, patient safety, and programs for the development and effective, safe, and sustained use of medicines are a feature of the journal, which

has also been accepted for indexing on PubMed Central. The manuscript management system is completely online and includes a very quick and fair peer-review system, which is all easy to use. Visit $\mathrm{http}: / / \mathrm{www}$.dovepress.com/testimonials.php to read real quotes from published authors.

Submit your manuscript here: http://www.dovepress.com/drug-design-development-and-therapy-journal 